Proc. Indian Acad. Sci. (Chem. Sci.), Vol. 102, No. 4, August 1990, pp. 481-496.

(C) Printed in India.

\title{
Analysis of the coordination geometry in copper complexes
}

\author{
C RAMAKRISHNAN* and Y S GEETHA ${ }^{\dagger}$ \\ Molecular Biophysics Unit, Indian Institute of Science, Bangalore 560012, India \\ ${ }^{\dagger}$ Present address: Protein Identification Resource, National Biomedical Research Foundation, \\ Georgetown University Medical Center, Washington DC 20007, USA
}

MS received 4 October 1989; revised 3 March 1990

\begin{abstract}
Geometrical parameters associated with a metal coordinated system have been analysed using data from 75 structures of copper complexes involving 370 coordination bonds. Coordination bond length and coordination bond angle, and deviation of the metal atom from the plane of equatorial ligand atoms have been analysed in detail for both oxygen and nitrogen ligand atoms. At the ligand end, the parameters defined closely follow that of the hydrogen bonded system and are related to the lone pair orbital directions. We find that (1) for oxygen ligands, the axial bond lengths are distinctly longer than the equatorial ones in octahedral (OCT) and square pyramidal (PY) geometries. The situation is reversed for trigonal bi-pyramidal (TBP) geometry with nitrogen ligands. (2) The coordination bond angle involving axial atoms varies between 130 and $180^{\circ}$ for the OCT case and 170 and $180^{\circ}$ for TBP geometry. Angles lying around $90^{\circ}$ range from $75-105^{\circ}$ with a few exceptions in OCT geometry. (3) The metal atom lies very nearly in the equatorial plane in TBP, while it deviates significantly in others. The extent of deviation can be explained qualitatively with the pull of the metal atom by the axial atoms. (4) The distribution of the ligand end parameters indicate that the bond direction strongly tends to cling to the associated orbital. When the ligand atom has two orbitals, the influence of the non-associated orbital is not significant and is far less as compared to hydrogen bonding.
\end{abstract}

Keywords. Copper coordination; coordination geometry; data analysis.

\section{Introduction}

The importance of metal ions in biological systems is quite well known. One of the very interesting features of a metal coordinated system is the concerted spatial arrangement of the ligands around the metal ion. In this paper, the crystal structure data on a number of copper coordinated systems are used to analyse the geometrical environment both at the metal and at the ligand ends. Except in special cases, the geometry exhibited by a coordinated system is often distorted. The aim of the present study is to get a quantitative idea of the range and dispersions of the various geometric parameters as well as the distortions from ideal geometrical situations.

Copper(II) has a $3 d^{9}$ outer electronic configuration and can form complexes of different geometries. The range of stereochemistries which have now been characterised for copper(II) and the factors which influence them have been summarised by Hathaway and Billing (1970). The major geometries that copper(II) takes up are octahedral (OCT) and square pyramidal (PY) and to a smaller extent square planar

\footnotetext{
*For correspondence
} 
(PL) and trigonal bipyramidal (TBP). On account of the close similarity between metal coordination and hydrogen bonding in so far as the ligand end is concerned, the formulation of parameters and the method of analysis employed in the present study closely follows that used in earlier studies from this group on hydrogen bonds (Ramachandran and Ramakrishnan 1967; Ramakrishnan and Prasad 1971; Mitra and Ramakrishnan 1977). The parameters at the metal end are of course very different.

\section{Definition of parameters}

The parameters that are used in the present study can be broadly classified as occurring at the metal end, associated with the geometry of coordination, or at the ligand end, associated with the lone pair orbitals of the ligand. The chief and most important parameter is the coordination bond length designated by $l$. This, in fact, can be taken to be associated with both ends, but for the present analysis it is grouped with metal end parameters.

The basis for defining the parameters at the ligand end is the same as that employed in the hydrogen bond studies done earlier in this group. There are three angular parameters $\xi, \zeta$ and $\theta$ at the ligand end, and these involve the direction of the lone pair orbitals at the ligand atom. When there are two lone pair orbitals at the ligand atom the choice of associated orbital is made using the same criteria as in earlier hydrogen bond studies. Depending on the type of the ligand, a ligand plane is defined. The definition of the ligand plane in the various cases is given in table 1 . While in (a) to (d) the lone pair orbitals are fixed in the ligand plane, for (e), where the nitrogen atom of the terminal amino group is the ligand atom, lone pair orbital is fixed

Table 1. The different ligand groups used and the relevance of the parameters at the ligand end, along with the number of examples used
for each type of ligand.

\begin{tabular}{|c|c|c|c|c|c|c|}
\hline \multirow[b]{2}{*}{ Type } & \multirow[b]{2}{*}{ Ligand } & \multicolumn{3}{|c|}{$\begin{array}{l}\text { Relevancy } \\
\text { parameters }\end{array}$} & \multirow{2}{*}{$\begin{array}{l}\text { Number of } \\
\text { examples } \\
\text { used }\end{array}$} & \multirow{2}{*}{$\begin{array}{l}\text { Definition } \\
\text { of ligand } \\
\text { plane }\end{array}$} \\
\hline & & $\xi$ & $\zeta$ & $\theta$ & & \\
\hline (a) & & yes & yes & yes & 101 & $\begin{array}{l}\text { Plane passing through } \\
\mathrm{C} \text { and } \mathrm{O} \text { and fitting } \\
\text { best with } \mathrm{X} \text { and } \mathrm{Y}\end{array}$ \\
\hline (c) & & yes & yes & yes & 24 & $\begin{array}{l}\text { Plane containing } \\
\text { lone pair orbitals (i.e., } \\
\text { perpendicular to the } \\
\text { plane XOY) }\end{array}$ \\
\hline & $\pi$ & yes & yes & yes & 9 & $\begin{array}{l}\text { Plane fitting best } \\
\text { with the peptide. } \\
\text { group }\end{array}$ \\
\hline (d) & $\mathrm{H} \quad \mathrm{C}$ & yes & yes & yes & 124 & Plane CNC \\
\hline (e) & $\mathrm{H}^{\prime} \mathrm{N}$ & no & no & yes & 32 & - \\
\hline
\end{tabular}




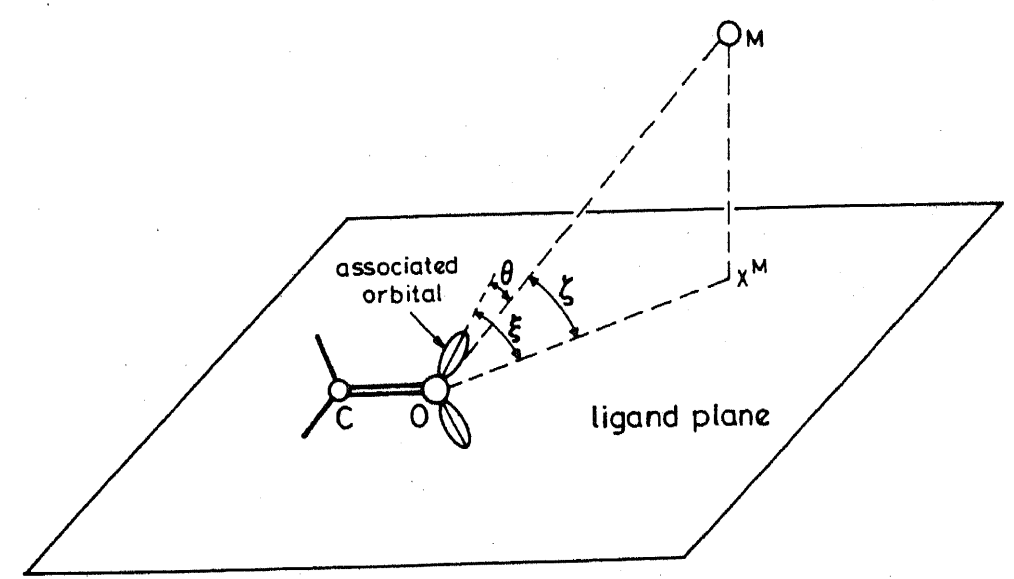

Figure 1. The parameters $\xi, \zeta$ and $\theta$ at the ligand end. The figure corresponds to case (a) of table $1 . \mathrm{M}$ - metal atom $(\mathrm{Cu}) ; X^{\mathrm{M}}$ - projection of metal-ligand direction onto the ligand plane. The orbital associated with the coordination bond is also shown.

tetrahedrally with respect to the three bonds meeting at the nitrogen atom, using the best-fit method.

The parameters $\xi, \zeta$ and $\theta$, as in the case of hydrogen bonds, are indicative of the spatial orientation of the M...L direction (M standing for the metal atom and $L$, the ligand atom) with the associated lone pair orbital. The parameter $\xi$, gives the angle between the associated lone pair orbital and the projection of the M...L direction on to the ligand plane, $\zeta$, the elevation of this direction from the ligand plane, and $\theta$, the geometrical angle between the M...L direction and the lone pair orbital. Figure 1 shows a schematic diagram of these parameters.

The relevance of the parameters and the number of examples of each type used in the various cases are given in table 1 . Only nitrogen and oxygen ligand atoms are used in this study as the number of examples involving other atoms such as halogens, sulphur etc., is too small to be subjected to any meaningful analysis.

At the metal end, apart from the parameter $l$ (coordination bond length), the other significant parameter is the coordination bond angle, and there are two kinds of these as described below.

In the octahedral arrangement, six ligand atoms surround the metal atom. By designating the axial atoms collectively as $\mathrm{A}$ and the four equatorial atoms collectively as $\mathrm{E}$, it is possible to define the following parameters.

In the OCT geometry there are ${ }^{6} C_{2} \cdot(15)$ possible angles. These fall into three categories, AMA, AMEE and EME. This parameter is represented by $\tau$ and the three subgroups are denoted by $\tau_{\mathrm{AA}}, \tau_{\mathrm{AE}}$ and $\tau_{\mathrm{EE}}$. Among these $\tau_{\mathrm{AA}}$ is always around $180^{\circ}$ and $\tau_{\mathrm{AE}}$ around $90^{\circ} . \tau_{\mathrm{EE}}$ however has different ranges of occurrence depending upon the coordination geometry.

For the ideal geometry (of OCT, PY and PL), the four equatorial atoms are coplanar and the line joining the two axial atoms passes through the metal atom and is also perpendicular to this plane. There are, however, distortions in any actual situation. A number of parameters have been defined to describe these distortions of the equatorial square and their values obtained (for details, see Geetha 1989). However only one parameter $\delta_{\mathrm{M}}$ is included in this paper. This gives the deviation of the metal atom from the plane which fits best with the four equatorial atoms (BP).

It can be seen that the parameter $\tau_{\mathrm{AA}}$ becomes irrelevant in the case of PY geometry 
Table 2. Relevant parameters at the metal end for different geometries.

\begin{tabular}{lllll}
\hline Parameter & OCT & PY & PL & TBP \\
\hline$l$ & yes & yes & yes & yes \\
$\tau_{\mathrm{AA}}$ & yes & no & no & yes \\
$\tau_{\mathrm{EE}}$ & yes & yes & yes & yes \\
$\tau_{\mathrm{AE}}$ & yes & yes & no & yes \\
$\delta_{\mathrm{M}}$ & yes & yes & yes & yes \\
\hline
\end{tabular}

as there is only one axial atom. Similarly any parameter connected with axial atoms becomes meaningless for PL geometry.

A summary of the relevant parameters at the metal end for different geometries is given in table 2 . It must be mentioned that the coordination bond length $(l)$ and the calculations. The other parame two parameters of great significance in energy proper coordination. These can prov collectively serve the purpose of obtaining the the positions of the prospective to be very useful in computer modelling wherein coordination and the pecked for the suitability of

The analysis has metal atom fixed in an appropriate manner (Geetha 1989). comprising twenty-nine OCT out with data from seventy-five copper(II) complexes, total of 370 coordination bonty-five PY, ten PL and eleven TBP geometries. A geometry, and number of bonds has been used for this analysis. The structures, in table 3 .

\section{Method of analysis}

The parameters, at the metal and the ligand ends as defined earlier using the basic crystal structure data viz ends as defined earlier, have been evaluated metal coordinate system. The values have the coordinates of atoms involved in the intervals and the distributions are studied been sorted out and grouped under suitable used type of parameter analysis and hed blotting histograms. This is a commonly problems (Einsphar and Bugg 1980, 1981. been used by different workers for similar 1984; Baker and Hubbard 1984; Yu et al 1985)

The first step in calculating the paramet al 1985). atoms. While there is no difficulty in the cases at the metal end is to identify the axial for OCT coordination. In an ideal situation of PY and TBP, there is some ambiguity are not uniquely defined and one can haven, the equatorial and axial ligand atoms is well-known that due to the Jahn-Tan have three possible combinations. However, it and thus there is a certain elongation -Teller effect, the symmetry is tetragonally distorted leading to their being defined as axial of bonds in two diametrically opposite directions away from the metal to be the axial positions. We have taken the two atoms farthest all cases the angle subtended, by the two however, we find that, interestingly, in vicinity of $180^{\circ}$, thereby confirming two atoms so chosen, at the metal lies in the this aspect gets further support from the diametrically opposite disposition. In fact, 
Table 3. The ligand molecules, geometry of coordination and the citation details of the structures used in the present analysis.

\begin{tabular}{|c|c|c|}
\hline $\begin{array}{l}\text { Ligand } \\
\text { molecule }\end{array}$ & $\begin{array}{l}\text { Geometry of } \\
\text { coordination }\end{array}$ & References \\
\hline L-Leu-L-Tyr & PY & Van der Helm et al (1975) \\
\hline Gly-Gly 2 W & PY & Kistenmacher and Szalda (1975) \\
\hline Bis $(\mathrm{N}$-acetyl-Gly) $2 \mathrm{~W}$ & OCT & Marcotrigiano et al (1976) \\
\hline Bis $(\mathrm{N}$-acetyl-Gly) $2 \mathrm{~W}$ & OCT & Udupa and Krebs (1978) \\
\hline Gly-L-Tyr $2 \mathrm{~W}$ & PY & Mosset and Bonnet (1977) \\
\hline bpy $\mathrm{Gly}-\mathrm{Cl}$ & PY & Neitzel and Desiderato (1975) \\
\hline Bis (2,3-di me py) $2 \mathrm{Cl} \& 2 \mathrm{Br}$ & PL & Stahlin and Oswald (1971) \\
\hline Imino diacetate $2 W$ & OCT & Podder et al (1979) \\
\hline L-Asp bpy W & PY & Antolini et al (1983) \\
\hline $\operatorname{Bis}(\delta-\mathrm{N}$-hydro-L-Orn) $2 \mathrm{Cl}$ & OCT & Stephens et al (1977) \\
\hline L-Asp im & PY & Antolini et al (1982) \\
\hline Bis(apa) 2W 2C104 & OCT & Mosset et al (1976) \\
\hline Butane di sulphonate-1, $44 \mathrm{~W}$ & OCT & Charbonnier et al (1977) \\
\hline Bis(2-amino-2-me-1-propanol) & PL & Muhonen (1981) \\
\hline Gly-L-Met & PY & Bear and Freeman (1976) \\
\hline L-Met-Gly & PY & Dehand et al (1979) \\
\hline Py-2,6 dicarboxylate & OCT & Sarchet and Loiseleur (1973) \\
\hline Bis(6-aminohexanoate) & OCT & Sjoberg et al (1973) \\
\hline Gly-Gly 9-me-adenine $4 \mathrm{~W}$ & PY & Kistenmacher et al (1976) \\
\hline Bis(tcp) di im & OCT & Wong et al (1976) \\
\hline Di aquo bis(salicylate) & PY & Jagner et al (1976) \\
\hline$\alpha-\beta$-didehydro Gly-Gly-His W & PL & Meester and Hodgson (1978) \\
\hline Bis(bpy) peroxo $2 \mathrm{SO} 4$ & PY & $\begin{array}{l}\text { Meester and Hodgson (1978) } \\
\text { Harrison and Hathaway (1980) }\end{array}$ \\
\hline Bis(bpy) I & TBP & $\begin{array}{l}\text { Harrison and Hathaway (1980) } \\
\text { Hathaway and Murphy (1980) }\end{array}$ \\
\hline Bis(bpy) $\mathrm{Br}$ & TBP & $\begin{array}{l}\text { Hathaway and Murphy (1980) } \\
\text { Hathaway and Murphy (1980) }\end{array}$ \\
\hline Gly-Gly cytosine & $\mathbf{P L}$ & $\begin{array}{l}\text { Hathaway and Murphy (1980) } \\
\text { Kistenmacher et al (1975) }\end{array}$ \\
\hline Bis(2-picolyl-phenyl ketonate) & PL & $\begin{array}{l}\text { Kistenmacher et al (1975) } \\
\text { Sieler et al (1976) }\end{array}$ \\
\hline (Salen) tu & PL & $\begin{array}{l}\text { Sieler et al (1976) } \\
\text { Ferrari et al (1976) }\end{array}$ \\
\hline (Salof) tu & PL & $\begin{array}{l}\text { Ferrari et al (1976) } \\
\text { Ferrari et al (1976) }\end{array}$ \\
\hline Bis(L-Leu) & OCT & $\begin{array}{l}\text { Ferrari et al (1976) } \\
\text { Fawcétt et al (1979) }\end{array}$ \\
\hline Bis(D, L-2-amino butyrate) & OCT & $\begin{array}{l}\text { Fawcétt et al (1979) } \\
\text { Fawcett et al (1979) }\end{array}$ \\
\hline Gly-L-His-Gly & $\mathrm{OCT}$ & $\begin{array}{l}\text { Fawcett et al (1979) } \\
\text { Meester and Hodgson (1977) }\end{array}$ \\
\hline Bis(L-Asp) & OCT & $\begin{array}{l}\text { Meester and Hodgson (1977) } \\
\text { Stephens et al (1975) }\end{array}$ \\
\hline Bis(L-Met) & OCT & $\begin{array}{l}\text { Stephens et al (1975) } \\
\text { Ou et al'(1978) }\end{array}$ \\
\hline 2,9-dime, phen Gly-Gly & PY & $\begin{array}{l}\text { Ou et al'(1978) } \\
\text { Simmons et al (1978) }\end{array}$ \\
\hline L-Val-L-Tyr 4W & PY & $\begin{array}{l}\text { Simmons et al (1978) } \\
\text { Amirthalingam and Muralidharan (1976) }\end{array}$ \\
\hline Nitrilo triacetate $\mathrm{W}$ & OCT & $\begin{array}{l}\text { Amirthalingam and Muralidharan (1976) } \\
\text { Whitlow (1973) }\end{array}$ \\
\hline Bis(py-2-acetate) $2 \mathrm{~W}$ & OCT & $\begin{array}{l}\text { Whitlow (1973) } \\
\text { Faure and Loiseleur (1975) }\end{array}$ \\
\hline $\mathrm{Bis}$ (dap) $\mathrm{ClO} 4$ & OCT & $\begin{array}{l}\text { Faure and Loiseleur (1975) } \\
\text { West et al (1980) }\end{array}$ \\
\hline Bis(propionate) 0, 5 dioxane & OCT & $\begin{array}{l}\text { West } \text { et al (1980) } \\
\text { Borel and Leclaire (1976b) }\end{array}$ \\
\hline Bis(propionate) $\beta$-picoline & OCT & $\begin{array}{l}\text { Borel and Leclaire (1976b) } \\
\text { Borel and Leclaire (1976a) }\end{array}$ \\
\hline $\operatorname{Bis}(\beta$-ala $) 4 \mathrm{~W}$ & OCT & $\begin{array}{l}\text { Borel and Leclaire (1976a) } \\
\text { Mitsui et al (1976) }\end{array}$ \\
\hline Gly-Gly phen $3 W$ & PY & $\begin{array}{l}\text { Mitsui et al (1976) } \\
\text { Lim et al (1976) }\end{array}$ \\
\hline Tetra- $\mu-\mathrm{N}-$ ac-Gly $2 \mathrm{~W}$ & OCT & $\begin{array}{l}\text { Lim et al (1976) } \\
\text { Udupa and Krebs (1979) }\end{array}$ \\
\hline Gly-Gly dmh & OCT & $\begin{array}{l}\text { Udupa and Krebs (1979) } \\
\text { Marzilli et al (1979) }\end{array}$ \\
\hline bea bpy NO3 $2 \mathrm{~W}$ & PY & $\begin{array}{l}\text { Marzilli et al (1979) } \\
\text { Druhdin' and Hathaway (1979) }\end{array}$ \\
\hline bea phen NO3 & PY & $\begin{array}{l}\text { Druhàn and Hathaway (1979) } \\
\text { Druhan atd Hathaway (1979) }\end{array}$ \\
\hline Aqua bis (LT) & PY & $\begin{array}{l}\text { Druhan atd Hathaway (1979) } \\
\text { Lanfredi et al (1979) }\end{array}$ \\
\hline Tetra aqua $\mu-9-$ me purine SO4 & OCT & $\begin{array}{l}\text { Lanfredi et al (1979) } \\
\text { Sletten and. Valand (1979) }\end{array}$ \\
\hline Aqua phen oxalato $W$ & PY & $\begin{array}{l}\text { Sletten and Valand (1979) } \\
\text { Fabretti et al (1985) }\end{array}$ \\
\hline
\end{tabular}


Table 3. (Continued)

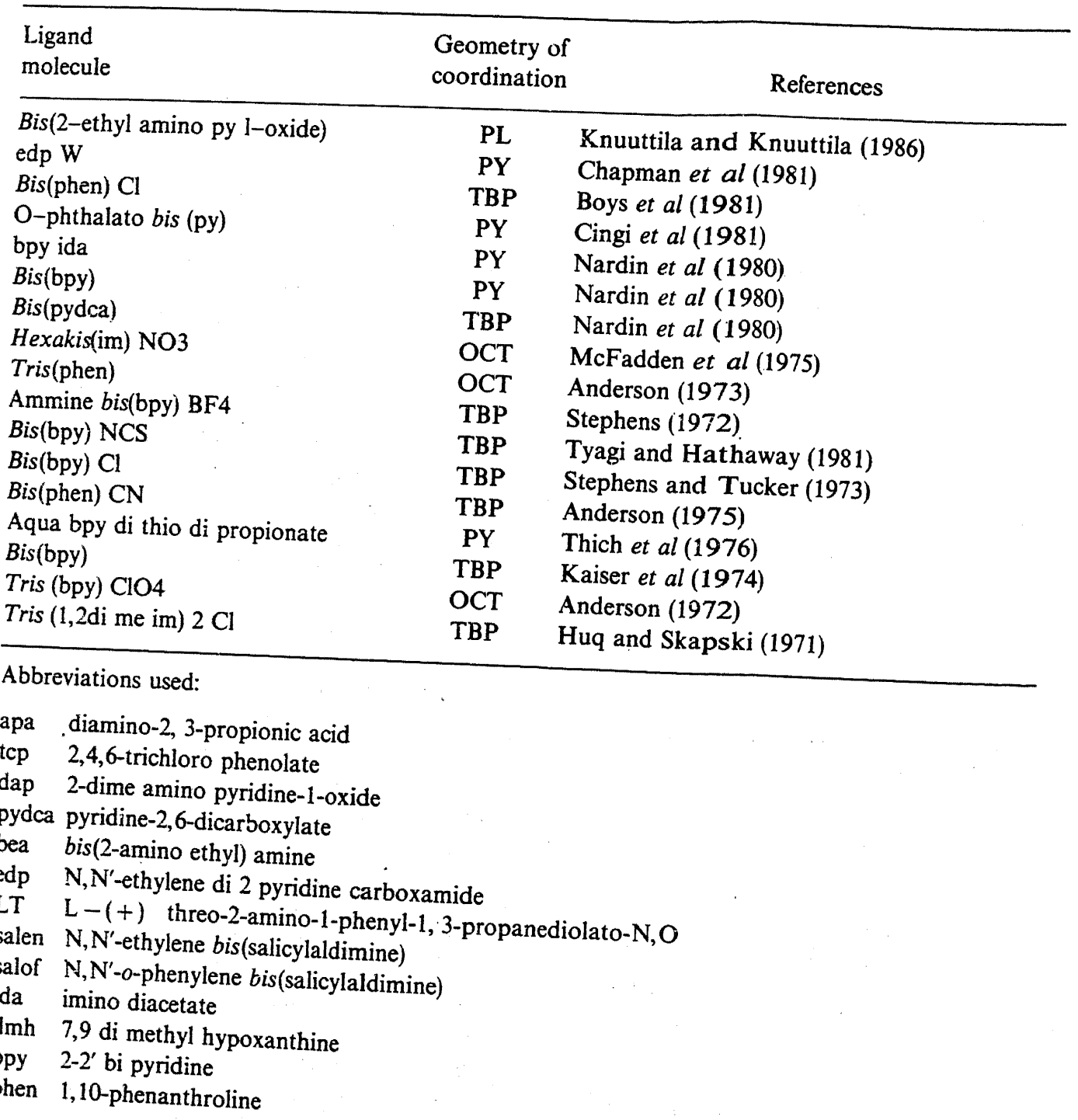

A computer program MCORD written in FORTRAN has been used to select the parameters mential atoms, fix the lone pair orbitals and also compute the various atoms or groups as input.

For the present study metal, as well as the geometrormation regarding the atoms that are bonded to the respective crystal structure studies as repordination have been directly taken from the made to find out whether there are anyorted therein. No further attempt has been metal at bonding distances.

\section{Results and discussion}

\subsection{Coordination bond length $(l)$} The parameter $l$, is found to vary from 1.8 to $3.0 \AA$ in the cases studied. The distribution
of values is shown in figure $2 \mathrm{a}$ as a histogiam which shows a prominent peak between 
Geometry of copper complexes

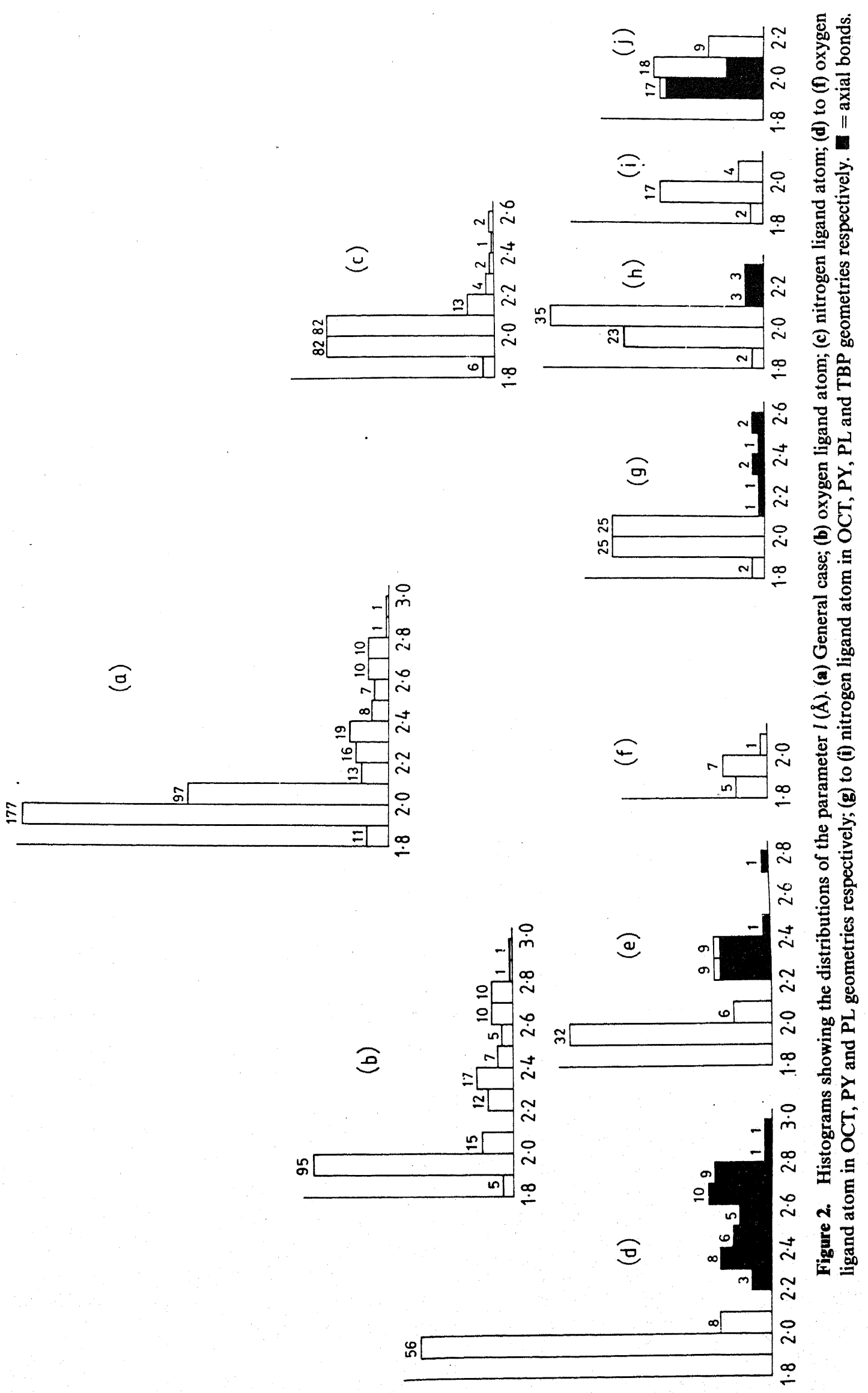


1.9 and $2.0 \AA$. In fact $47.8 \%$ of the values lie in this range. The distribution falls very steeply on the lower value side. On the higher side, however, there is a two-step fall followed by a plateau.

In order to look at the variation in more depth, the distribution of this parameter corresponding to the two ligand atoms $(\mathrm{O}$ and $\mathrm{N})$ as well as for different coordination geometries are drawn in figures $2 b-2 j$.

The distribution for the oxygen ligand case (fugure $2 b$ ) shows an interesting aspect. No values fall between $2 \cdot 1$ and $2 \cdot 2 \AA$, thereby producing two regions. The first region shows a pronounced peak between 1.9 and $2.0 \AA$ (similar to the one shown in figure $2 \mathrm{a}$ ) and there is a near even distribution between 2.2 and $2.8 \AA$ in the second region with a small peak between $2 \cdot 3$ and $2 \cdot 4 \AA$.

This same trend is also exhibited in the sub-distributions corresponding to the OCT and PY cases (figure $2 \mathrm{~d}$ and $2 \mathrm{e}$ ) and is absent in the PL case (figure $2 \mathrm{f}$ ).

Further examination of the values show that all the values between 2.2 and $3.0 \AA$ (63) belong to axial positions of either OCT or PY geometry and none of the examples in the range 1.8-2.1 $\AA$ correspond to axial orientation. In a way this is to be expected since the indentification of axial bonds has been made making use of the length, in the OCT geometry. What makes this interesting is that there is a small but definite gap separating the range of axial and equatorial lengths. The shortest axial bond is longer than the longest equatorial bond. The fact that this aspect is reflected in the case of PY geometry too is an indirect justification for choosing the two longest bonds as axial in the case of OCT geometry.

Figure $2 \mathrm{f}$ which gives the distribution for PL geometry shows a range of $1.8-2 \cdot 1 \AA$ with a peak between 1.9 and $2.0 \AA$. That there are no examples with lengths greater than $2 \cdot 2 \AA$ is to be expected since this geometry does not have any axial bond. It can be observed that all the five examples between 1.8 and $1.9 \AA$, shown in figure $2 b$, do have this coordination. Thus it can be deduced that in this coordination there is a tendency for the bonds to be short.

An analysis similar to the above can be made using the histograms shown in figure $2 \mathrm{c}$ and figures $2 \mathrm{~g}-2 \mathrm{j}$ which correspond to examples having nitrogen as the ligand atom. The distribution shows a broad peak between 1.9 and $2.1 \AA$ and falls off sharply on either side. This trend is equally well reflected for the OCT geometry (figure $2 \mathrm{~g}$ ) and to a lesser extent TBP (figure $2 \mathrm{j}$ ). The peak value lies between 1.9 and $2.0 \AA$ for PL and between $2 \cdot 0$ and $2 \cdot 1 \AA$ for PY geometries.

Unlike the case of oxygen ligand atoms, there are no two well-separated regions in these cases. In order to know whether there is any dependency of the range on the position of the ligand (axial or equatorial), the individual examples were looked into. The distribution of the length for the axial cases are shown as shaded regions in the histograms $2 \mathrm{~g}, 2 \mathrm{~h}$ and $2 \mathrm{j}$. The lengths always tend to be on the higher side in the case of OCT and PY geometries (figures $2 \mathrm{~g}$ and $2 \mathrm{~h}$ ). Thus the trend is similar to the one observed with the oxygen ligand atom and described earlier.

The distribution for TBP geometry (figure $2 \mathrm{j}$ ), however, presents a very different and interesting situation. Almost all the examples in the range 1.9-2.0 $\AA$ belong to the axial orientation and this length does not go beyond $2 \cdot 1 \AA$. This means, that unlike the cases of OCT and PY coordination, the axial bond is always shorter than the equatorial bond. In fact, this aspect was checked in the individual cases and found
to be true.

The ranges for bond lengths observed in the different cases are collected and given in table 4 along with the average values and their standard deviations. 
Table 4. Ranges, averages (Av) and standard deviations (SD) (in $\AA$ ) for coordination bond lengths $(l)$ in different geometries, and for different dispositions of the ligand atoms.

\begin{tabular}{|c|c|c|c|c|c|}
\hline Geometry & & $\mathrm{O}_{\mathrm{Eq}}$ & $\mathrm{O}_{\mathrm{Ax}}$ & $\mathrm{N}_{\mathrm{Eq}}$ & $\mathrm{N}_{\mathrm{Ax}}$ \\
\hline & Range & $1 \cdot 9-2 \cdot 1$ & $2 \cdot 2-3 \cdot 0$ & $1 \cdot 8-2 \cdot 1$ & $2 \cdot 1-2 \cdot 6$ \\
\hline \multirow[t]{3}{*}{ OCT } & $\mathrm{Av}$ & 1.97 & 2.55 & 1.99 & $2 \cdot 38$ \\
\hline & SD & 0.03 & $0 \cdot 19$ & 0.04 & $0 \cdot 16$ \\
\hline & Range & $1.9-2 \cdot 4$ & $2 \cdot 2-2 \cdot 8$ & $1 \cdot 8-2 \cdot 1$ & $2 \cdot 1-2 \cdot 3$ \\
\hline \multirow[t]{3}{*}{ PY } & Av & 1.98 & $2 \cdot 34$ & 1.99 & $2 \cdot 21$ \\
\hline & $\mathrm{SD}$ & 0.08 & 0.13 & 0.05 & 0.06 \\
\hline & Range & $1 \cdot 8-2 \cdot 1$ & & $1 \cdot 8-2 \cdot 1$ & \\
\hline \multirow[t]{3}{*}{ PL } & Av & 1.91 & & 1.96 & \\
\hline & $\mathrm{SD}$ & 0.03 & & 0.04 & \\
\hline & Range & & & $1 \cdot 9-2 \cdot 2$ & $1 \cdot 9-2 \cdot 1$ \\
\hline \multirow[t]{2}{*}{ TBP } & Av & & & 2.09 & 1.99 \\
\hline & $\mathrm{SD}$ & & & 0.04 & 0.01 \\
\hline
\end{tabular}

\subsection{Coordination bond angle $(\tau)$}

As mentioned in an earlier section, there can be three types of angles, $\tau_{\mathrm{AA}}, \tau_{\mathrm{AE}}$ and $\tau_{\mathrm{EE}}$, depending upon the ligand positions. It is apparent that the values of $\tau_{\mathrm{AA}}$ must be distributed around $180^{\circ}$ and those of $\tau_{\mathrm{AE}}$ around $90^{\circ}$. The value of $\tau_{\mathrm{EE}}$ however can have a double distribution, one around $90^{\circ}$ and another around $180^{\circ}$ in the case of OCT, PY and PL, and $120^{\circ}$ for TBP. The ranges, averages and standard deviations of the angles for different geometries are given in table 5 , and the distributions in figures $3 a-3 f$.

The distribution for $\tau_{\mathrm{AA}}$ is shown in figure 3a. There is a predominant peak between 170 and $180^{\circ}$. However, the values can be as low as $130^{\circ}$, though the number of values between 130 and $170^{\circ}$ is only eight. This parameter is applicable only to OCT and TBP geometries. In figure $3 \mathrm{a}$, the distribution for TBP is shown as hatched and all the 11 examples lie between 170 and $180^{\circ}$. Thus the tendency of the AMA direction to deviate from collinearity is less for TBP than for OCT coordination. In a semi-quantitative way the average and standard deviation of this parameter for the two cases reflect this aspect (table 5).

The distribution of the values which lie around $90^{\circ}$ is shown in figure $3 \mathrm{~b}-3 \mathrm{e}$, with the distribution for $\tau_{\mathrm{AE}}$ being shaded. In all the cases, the peak of the distribution is between 85 and $95^{\circ}$. However, in the case of OCT geometry, there are some examples with values as low as $45^{\circ}$ and as high as $135^{\circ}$. But their number is small compared to the peak value. The same trend is observed in PY also and the distribution is more skewed towards the higher side of $90^{\circ}$. In the case of TBP, there are no examples outside the range $75-105^{\circ}$ for $\tau_{\mathrm{AE}}$ (figure $3 \mathrm{e}$ ).

Since the angles around $90^{\circ}$ can have contributions from both $\tau_{\mathrm{AE}}$ and $\tau_{\mathrm{EE}}$, it is worthwhile to examine which of these will have a greater spread (this is applicable to OCT and PY cases, since $\tau_{\mathrm{AE}}$ is not relevant to PL and the value of $\tau_{\mathrm{EE}}$ will be distributed around $120^{\circ}$ for TBP). From the shaded region shown in figure $3 b$ and $3 c$, it is clear that the spread arises from $\tau_{\mathrm{AE}}$. This spread is more in the case of OCT than PY. In the latter distribution, there is an isolated example between 45 and $55^{\circ}$ as well 
Table 5. Ranges, averages (Av) and standard deviations (SD) (in degrees) for coordination bond angles $(\tau)$ in different geometries.

\begin{tabular}{lcccc}
\hline Geometry & & $\tau_{\mathrm{AA}}$ & $\tau_{\mathrm{AE}}$ & $\tau_{\mathrm{EE}}$ \\
\hline \multirow{4}{*}{ OCT } & Range & $130-180$ & $45-130$ & $75-105$ \\
& $\mathrm{Av}$ & $171 \cdot 1$ & $90 \cdot 2$ & 89.9 \\
& $\mathrm{SD}$ & 13.9 & 11.8 & 5.0 \\
$\mathrm{PY}$ & Range & & $75-115$ & $75-115$ \\
& $\mathrm{Av}$ & & 95.7 & 90.3 \\
& $\mathrm{SD}$ & & 8.5 & 7.5 \\
$\mathrm{PL}$ & Range & & & $75-105$ \\
& $\mathrm{Av}$ & & & 90.2 \\
& $\mathrm{SD}$ & & & 4.7 \\
TBP & Range & $170-160$ & $75-105$ & $95-145$ \\
& $\mathrm{Av}$ & 175.9 & 89.9 & 119.8 \\
& $\mathrm{SD}$ & 1.2 & 6.7 & 11.9 \\
\hline
\end{tabular}

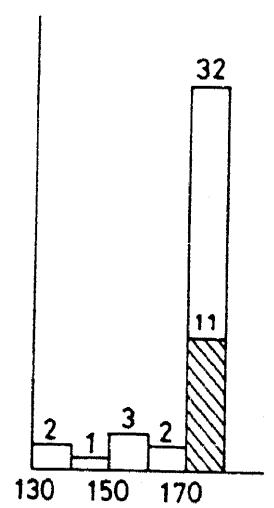

(a)

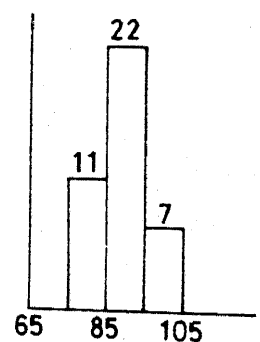

(d)

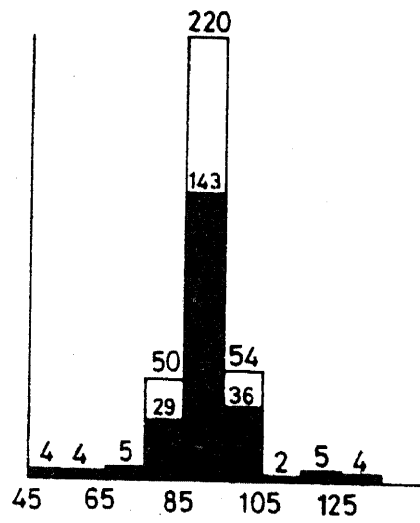

(b)

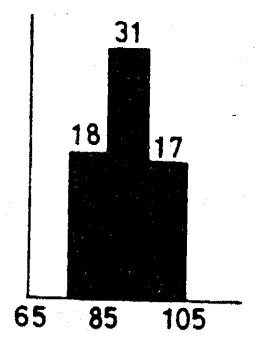

(e)

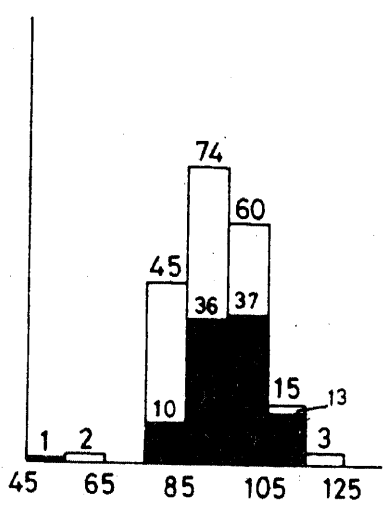

(c)

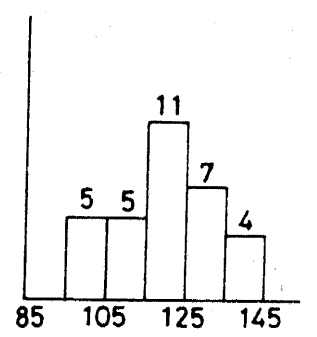

(f)

Figure 3. Histograms showing the distributions of the parameter $\tau\left({ }^{\circ}\right)$; (a) $\square=\tau_{A A}$ for OCT, 园 $=\tau_{\mathrm{AA}}$ for TBP, (b) $\square=\tau_{\mathrm{AE}}$ for OCT, $\square=\tau_{\mathrm{EE}}$ for OCT, (c) $\square=\tau_{\mathrm{AE}}$ for PY, $\square=\tau_{\mathrm{EE}}$ for PY (d) $\tau_{E E}$ for PL, (e) $\tau_{A E}$ for TBP, and (f) $\tau_{E E}$ for TBP.

as three examples between 115 and $125^{\circ}$. Actually, three of these four occur in the compound L-valine-L-tyrosine copper(II). $4 \mathrm{H}_{2} \mathrm{O}$ (Amirthalingam and Muralidharan 1976). In view of the fact that there are no examples between 55 and $75^{\circ}$, this can be treated as an exception.

The distribution of $\tau_{\mathrm{EE}}$ shows a more uniform pattern in OCT, PY and PL 
geometries. The range is $75-105^{\circ}$ for OCT, PL and $75-115^{\circ}$ for PY and hence for practical purposes the range can be taken as $75-105^{\circ}$. There are two examples between 55 and $65^{\circ}$ for PY geometry, with no examples between 65 and $75^{\circ}$ and 35 examples between 75 and $85^{\circ}$. Therefore these two examples can be treated as exceptions.

In the case of TBP, $\tau_{\mathrm{AE}}$ ranges from $75-105^{\circ}$ and $\tau_{\mathrm{EE}}$ has a broader range between 95 and $145^{\circ}$. From table 5 , it can be seen that in the OCT case the standard deviation is smallest for $\tau_{\mathrm{EE}}$ and increases for $\tau_{\mathrm{AE}}$ and $\tau_{\mathrm{AA}}$. It is interesting to note that this trend is exactly opposite to that for the TBP case. $\tau_{\mathrm{AE}}$ shows greater clustering, compared to $\tau_{\mathrm{EE}}$ for TBP geometry.

\subsection{Deviation of the metal from the best plane $\left(\delta_{\mathrm{M}}\right)$}

The general distribution for this parameter is given in figure $4 \mathrm{a}$. The distributions of the parameter for OCT, PY, PL and TBP are shown in figures $4 \mathrm{~b}-4 \mathrm{e}$. It can be seen that the range is very narrow $(0-0.05 \AA)$ for TBP, and largest $(0-0.4 \AA)$ for PY geometry. The range for OCT is $0-0.25 \AA$ and $0-0.1 \AA$ for PL geometry.

The average value of the deviation for TBP is $0.006 \AA$ and the standard deviation is $0.003 \AA$, indicating that the metal is nearly in the plane of the equatorial atoms. The corresponding values for PL and OCT cases are $0.04 \AA(\sigma=0.02)$ and $0.08 \AA(\sigma=$ 0.07 ) respectively indicating that the metal is more deviated from the plane in these cases. The largest value however is found for the PY case with an average of $0.19 \AA$ and standard deviation of $0.09 \AA$. There are two examples between 0.35 and $0.4 \AA$, which are very large as compared to others.

That the deviation of the metal atom is largest for the PY case can be understood since in this case the metal atom is subjected to an asymmetric pull by the lone axial atom. In fact, an interesting observation made in the present study is that the shift of the metal atom in all the PY cases is on the same side of the best plane as the axial ligand. In the OCT and TBP cases, the deviations, as expected, are smaller than

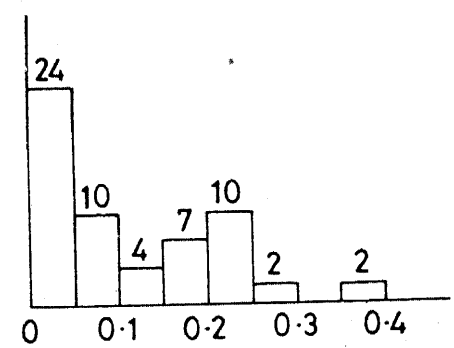

(a)

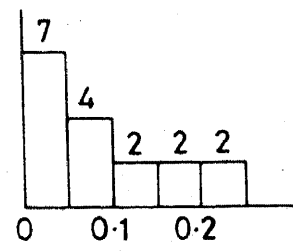

(b)

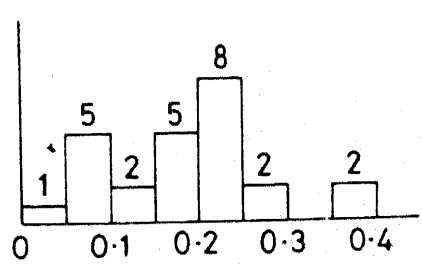

(c)

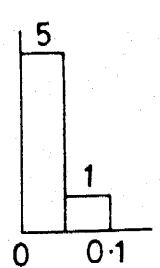

(d)

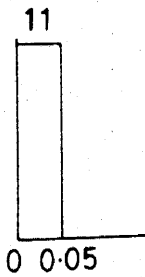

(e)

Figure 4. Histograms showing the distributions of the parameter $\delta_{M}(\AA)$. (a) General; (b) OCT; (c) PY; (d) PL; and (e) TBP geometries. 
for PY in view of the symmetric pull by the two axial atoms. In the case of PL, the metal is not subjected to any axial pull.

The three parameters discussed so far involve the metal atom. In addition, four other parameters pertaining to virtual bond lengths and virtual bond angles connected with the equatorial square have also been defined, and the data collected and analysed. The details of these in the form of histograms are available elsewhere (Geetha 1989). The results indicate that the ideal square can be distorted up to $0.4 \AA$ for its side and $10^{\circ}$ for its angle. The deviation of the equatorial atoms from the best plane ranges from 0 to $0.25 \AA$ (Geetha 1989).

\subsection{Ligand end parameters}

The distribution for the three parameters defined at the ligand end, viz. $\theta, \zeta$ and $\xi$, are shown in figures $5 \mathrm{a}, 5 \mathrm{~d}$ and $5 \mathrm{~g}$ respectively. The individual distributions for the oxygen ligand atoms are shown in figure $5 \mathrm{~b}, 5 \mathrm{e}$ and $5 \mathrm{~h}$ and the corresponding histograms for the nitrogen ligand atoms are shown in figures $5 \mathrm{c}, 5 \mathrm{f}$ and $5 \mathrm{i}$ respectively.

The general distribution for the three parameters have the common feature in that the peak occurs for the range $0-10^{\circ}$ and a considerable percentage of values lies in this range $(59 \cdot 6,81 \cdot 4,71 \cdot 7 \%$ respectively). The range for these parameters can be taken to be $0-60^{\circ}$, with a few examples $(1 \%)$ lying outside this range. The distribution for $\theta$ falls off more gradually than for the other two parameters.

From the distributions of the three parameters for oxygen and nitrogen ligand atoms, we observe (i) the spread of values is larger in the case of oxygen than for nitrogen, (ii) the fall-off in the case of nitrogen is much steeper than for oxygen.

In order to compare the present situation with that existing in hydrogen bond cases, the corresponding distributions for $\theta, \zeta$ and $\xi$ are shown in figures $5 \mathrm{j}, 5 \mathrm{k}$ and 51 respectively. These have been drawn using data from figures $10 \mathrm{~d}, 5 \mathrm{~b}$ and $7 \mathrm{~b}$ of Mitra and Ramakrishnan (1977) for O-H..O bonds and the updated data of figures $13 \mathrm{~b}, 5 \mathrm{~b}$ and $8 \mathrm{a}$ of Ramakrishnan and Prasad (1971), obtained from Prasad (1972), for $\mathrm{N}-\mathrm{H}$... O bonds.

In the distribution for $\theta$, the peak is shifted to the right $\left(20-30^{\circ}\right)$ as compared to the present case $\left(0-10^{\circ}\right)$. The peak for $\zeta$ is between 0 and $10^{\circ}$ for the hydrogen bond case also. In the case of $\xi$, the peak is very broad $\left(0-20^{\circ}\right)$. Comparing the corresponding histograms for the coordination bonds, we observe that the range is broader and falls off more gradually in the hydrogen bond cases. Based upon this, it can be said that the M...L bond has a much stronger tendency to cling to the orbital with which it is associated. This can also be interpreted to mean that the direction of the coordination bond is more highly influenced by the lone pair orbitals than that of the hydrogen bond.

It was shown in the earlier studies on hydrogen bonds that the distribution of $\xi$ was dependent on whether the acceptor oxygen atom is the recipient of one hydrogen bond or two. In addition there was a definite distinction in the distribution when the projection of the H...O direction falls in between orbitals as compared to the situation when it falls outside the orbitals. From the data given in table 9 of Mitra and Ramakrishnan (1977), it is clear that the peak which is between 0 and $10^{\circ}$ for the two bond acceptor case (irrespective of the H...O projection position) as well as for the range $20-30^{\circ}$ when the projection falls between orbitals.

In order to find out whether a similar effect is observable in the present case, the 


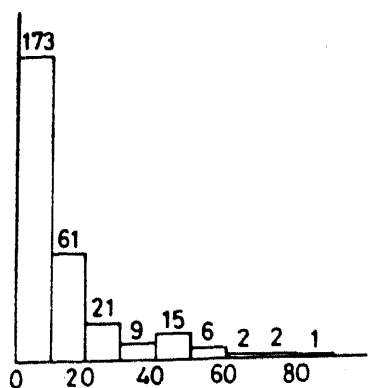

(a)

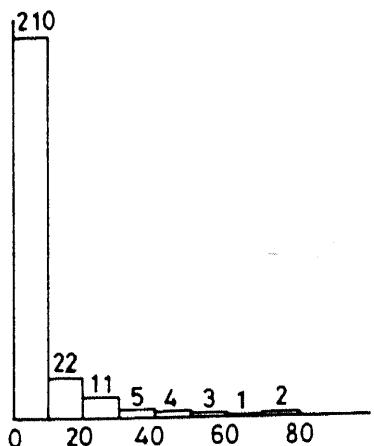

(d)

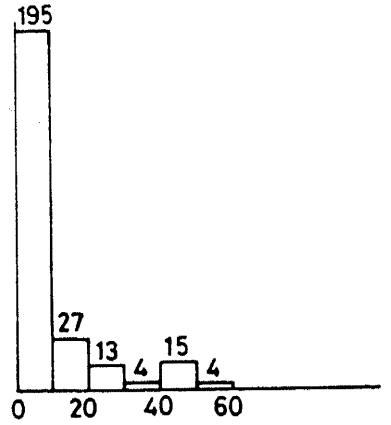

(g)

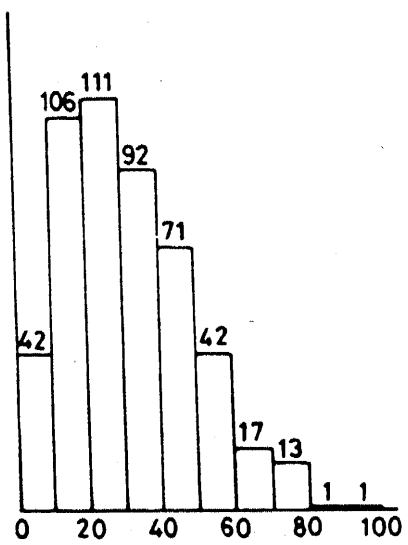

(j)

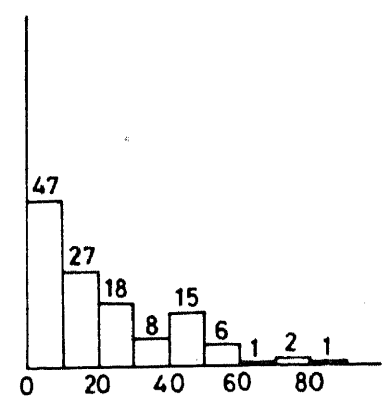

(b)

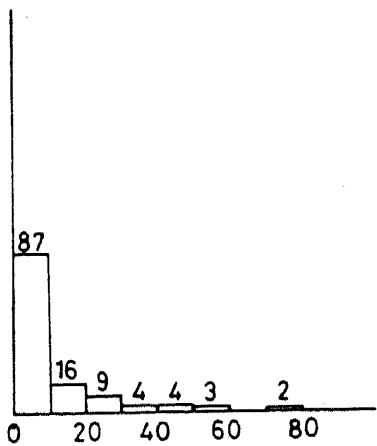

(e)

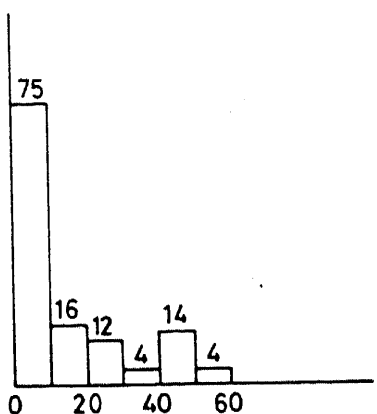

(h)

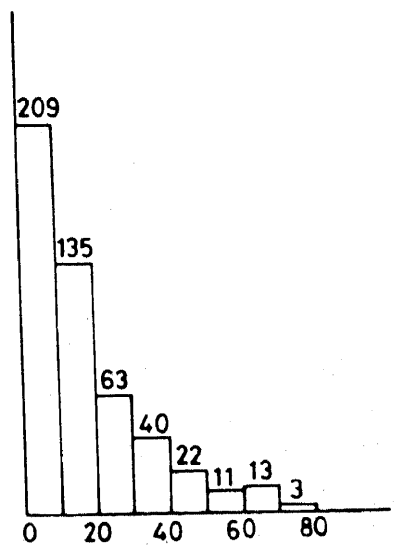

(k)

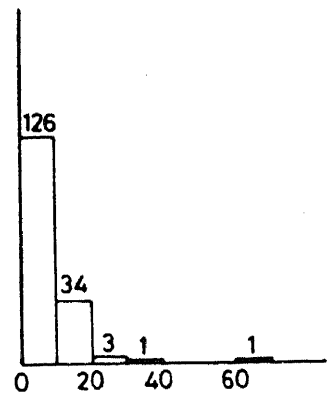

(c)

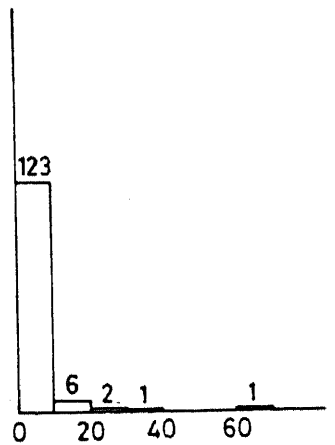

(f)

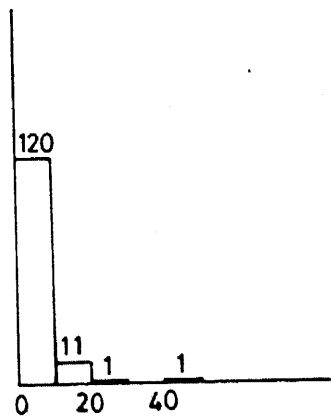

(i)

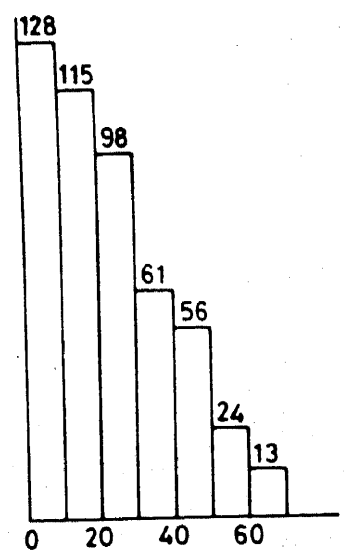

(1)

Figure 5. Histograms showing the distributions of the ligand end parameters: (a)-(c) distribution of $\theta$; (d)-(f) distribution of $\zeta$; and (g)-(i) distribution of $\xi$; all in degrees. (a), (d) and $(\mathrm{g})$ general; (b), (e) and (h) oxygen ligand atom; (c), (f) and (i) nitrogen ligand atom. The corresponding acceptor end parameters for hydrogen bonds are: (j) distribution of $\theta$; (k) distribution of $\zeta$; and (l) distribution of $\xi$. 


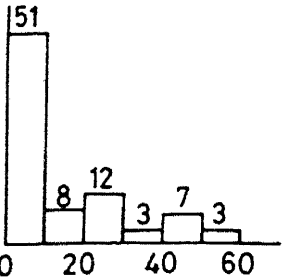

(a)

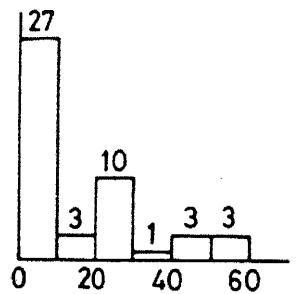

(c)

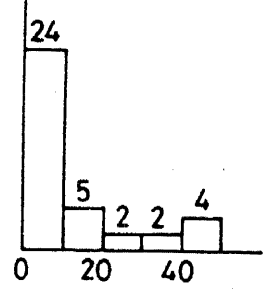

(d)

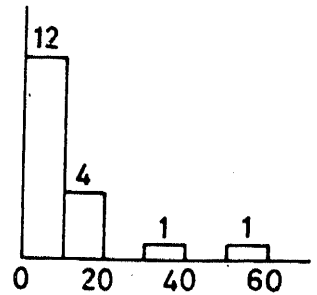

(e)

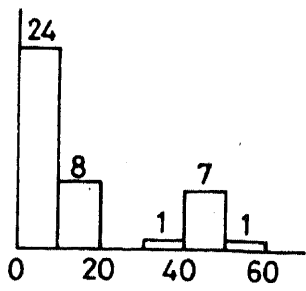

(b)

Figure 6. Histograms showing the distributions of $\xi$ in different cases. (a) One-bond acceptor; (b) two-bond acceptor; and (c) one-bond acceptor; with the projection lying in-between the orbitals; (d) one-bond acceptor, with the projection lying outside the orbitals; (e) two-bond acceptor, with the projection lying in-between the orbitals; and (f) two-bond acceptor, with the projection lying outside the orbitals.

distributions of $\xi$ under different situations are given in figures $6 \mathrm{a}-\mathrm{f}$. The histograms clearly indicate the absence of such an effect. In fact, the peak position lies between 0 and $10^{\circ}$ in all the histograms. This shows that the influence of the other non-associated orbital on the bonding direction is far less and is also independent of whether the projection lies between the orbitals or outside the orbitals in the ligand plane.

\section{Acknowledgements}

The authors would like to thank Dr N V Joshi for useful and interesting discussions. One of us (YSG) would like to thank the University Grants Commision for financial support.

\section{References}

Amirthalingam V and Muralidharan K V 1976 Acta Cryst. B32 3153

Anderson O P 1972 J. Chem. Soc., Dalton Trans. 2597

Anderson O P 1973 J. Chem. Soc., Dalton Trans. 1237

Anderson O P 1975 Inorg. Chem. 14730

Antolini L, Marcotrigiano G, Menabue L and Pellacini G E 1983 Inorg. Chem. 22141

Baker E N and Hubbard R E 1984 Prog. Biophys. Mol. Biol. 4

Bear C A and Freeman H C 1976 Acta Cryst. B32 2534

Borel P M M and Leclaire A 1976a Acta Cryst. B32 1273

Borel P M M and Leclaire A 1976b Acta Cryst. B32 1275

Boys D, Escobar C and Carrera S M 1981 Acta Cryst. B37 351

Chapman R L, Stephens F S and Vagg R S 1981 Acta Cryst. B37 75 
Charbonnier P F, Faure R and Loiseleur H 1977 Acta Cryst. B33 3759

Chiari G and Ferraris G 1982 Acta Cryst. B38 2331

Cingi M B, Lanfredi A M M, Tiripicchio A and Camellini M T 1981 Acta Cryst. B37 2159

Dehand J, Jordanov J, Keck F, Mosset A, Bonnet J J and Galy J 1979 Inorg. Chem. 181543

Druhan G and Hathaway B J 1979 Acta Cryst. B35 344

Einsphar H and Bugg C E 1980 Acta Cryst. B36 264

Einsphar H and Bugg C E 1981 Acta Cryst. B37 1044

Fabretti A C, Franchini G and Zannini P 1985 Inorg. Chim. Acta 105187

Faure P R and Loiseleur H 1975 Acta Cryst. B31 1472

Fawcett T G, Ushay M, Rose J P, Lalancette R A, Potenza J A and Schugar H J 1979 Inorg. Chem. 18327

Ferrari M B, Fava G G and Pellizi C 1976 Acta Cryst. B32 901

Geetha Y S 1989 Studies on geometrical aspects of metal coordination, $\mathrm{Ph}$ D thesis, Indian Institute of Science, Bangalore

Harrison W D and Hathaway B J 1980 Acta Cryst. B36 1069

Hathaway B J and Billing D E 1970 Coordination Chem. Rev. 5143

Hathaway B J and Murphy A 1980 Acta Cryst. B36 295

Huq F and Skapski A C 1971 J. Chem. Soc. A 1927

Jagner S, Hazell R G and Larsen K P 1976 Acta Cryst. B32 548

Kaiser J, Brauer G, Schroder A F, Taylor I F and Rasmussen S E 1974 J. Chem. Soc., Dalton Trans. 1490

Kistenmacher T J, Marzilli L G and Szalda D J 1976 Acta Cryst. B32 186

Kistenmacher T J and Szalda D J 1975 Acta Cryst. B31 1659

Kistenmacher T J, Szälda D J and Marzilli L G 1975 Acta Cryst. B31 2416

Knuuttila P and Knuuttila H 1986 Acta Cryst. C42 989

Lanfredi A M M, Tiripicchio A and Camellini M T 1979 Acta Cryst. B35 349

Lim M C, Sinn E and Martin R B 1976 Inorg. Chem. 15807

Marcotrigiano G, Pellacani G C, Battaglia L P and Corradi A B 1976 Cryst. Struct. Commun. 5923

Marzilli L G, Wilkowski K, Chiang C C and Kistenmacher T J 1979 J. Am. Chem. Soc. 1017504

McFadden D L, McPhail A T, Garner C D and Mabbs F E 1975 J. Chem. Soc., Dalton Trans. 263

Meester P D and Hodgson D J 1977 Acta Cryst. B33 3505

Meester P D and Hodgson D J 1978 Inorg. Chem. 17440

Mitra J and Ramakrishnan C 1977 Int. J. Pept. Protein Res. 927

Mitsui Y, litaka Y and Sakaguchi H 1976 Acta Cryst. B32 1634

Mosset P A and Bonnet J J 1977 Acta Cryst. B33 2807

Mosset P A, Bonnet J J and Jeanin Y 1976 Acta Cryst. B32 591

Muhonen H 1981 Acta Cryst. B37 951

Nardin G, Randaccio L, Bonomo R P and Rizzarelli E 1980 J. Chem. Soc., Dalton Trans. 369

Neitzel C J and Desiderato R 1975 Cryst. Struct. Commun. 4333

Ou C C, Powers D A, Thich J A, Felthouse T R, Hendrickson D N, Potenza J A and Schugar H J 1978 Inorg. Chem. 1734

Podder A, Dattagupta J K, Saha N N and Saengar W 1979 Acta Cryst. B35 53

Prasad N 1972 Theory of biopolymer conformations, Ph D thesis, University of Madras

Ramachandran G N and Ramakrishnan C 1967 Fibrous proteins (ed) W G Crewther (Australia: Butterworths) p.71

Ramakrishnan C and Prasad N 1971 Int. J. Protein. Res. 3209

Sarchet P C and Loiseleur H 1973 Acta Cryst. B29 1345

Sieler V J, Kaiser J, Richter R and Schmidt W 1976 Acta Cryst. B32 452

Simmons C J, Lundeen M and Seff K 1978 Inorg. Chem. 171429

Sjoberg B, Osterberg R and Soderquist R 1973 Acta Cryst. B29 1136

Sletten E and Valand E 1979 Acta Cryst. B35 840

Stahlin W and Oswald H R 1971 Acta Cryst. B27 1368

Stephens F S 1972 J. Chem. Soc., Dalton Trans. 1350

Stephens F S and Tucker P A 1973 J. Chem. Soc., Dalton Trans. 2293

Stephens F S, Vagg R S and Williams P A 1975 Acta Cryst. B31 841

Stephens F S, Vagg R S and Williams. P A 1977 Acta Cryst. B33 438

Taylor R, Kennard O and Verischel W 1983 J. Am. Chem. Soc. 1055761

Taylor R, Kennard O and Verischel W 1984 Acta Cryst. B40 280

Thich J A, Lalancette R A, Potenza J A and Schugar H J 1976 Inorg. Chem. 152731

Tyagi S and Hathaway B J 1981 J. Chem. Soc., Dalton Trans. 2029 
Udupa M R and Krebs B 1978 Inorg. Chim. Acta 31251

Udupa M R and Krebs B 1979 Inorg. Chim. Acta 371

Van der Helm D, Ealick S E and Burks J E 1975 Acta Cryst. B31 1013

West D X, Pavkovic S F and Brown J N 1980 Acta Cryst. B36 143

Whitlow S H 1973 Inorg. Chem. 122286

Wong R Y, Palmer K J and Tomimatsu Y 1976 Acta Cryst. B32 567

Yu H A, Karplus M and Hendrickson W A 1985 Acta Cryst. B34 191 